\title{
Fundamentos epistemológicos del ReAlismo JURÍDICO: Empirismo, Neopositivismo y aCtOS DE HABLA ${ }^{1}$ Epistemological Foundations of Legal Realism: Empiricism, Logical Positivism and Speech Acts
}

\author{
Ángel Manuel Molina Lara ${ }^{2}$ \\ Investigador independiente, Caracas, Venezuela \\ Carlos Eduardo Durán Chávez ${ }^{3}$ \\ Universidad Metropolitana, Quito, Ecuador \\ Universidad Técnica Particular de Loja, Loja, Ecuador
}

\section{Resumen}

El presente artículo describe las relaciones directas e indirectas entre el realismo jurídico y corrientes filosóficas como el empirismo británico, el neopositivismo y la filosofía del lenguaje ordinario. Se presenta el realismo jurídico en su contexto de aparición, para luego exponer a los principales representantes del empirismo británico, antecedente y fundamento epistemológico del realismo jurídico. También se sintetizan las características distintivas del neopositivismo y su afinidad teórica con el realismo jurídico. Después se muestran los vínculos entre la filosofía del lenguaje ordinario y el realismo jurídico desde la teoría de los actos de habla. Se concluye que la renovada vigencia del realismo jurídico requiere una comprensión de sus fundamentos filosóficos.

\section{Palabras clave}

Realismo jurídico, empirismo, neopositivismo, actos de habla.

\section{Summary}

This paper describes direct and indirect relations between legal realism and philosophical movements such as British empiricism, logical positivism and ordinary language philosophy. Legal realism is showed in its emergence context, and thereafter the paper exposes the main representatives of British empiricism, background and epistemological foundation of legal realism. Distinctive features of logical positivism and its theoretical affinity with legal realism are also synthesized. Afterwards, the links between the philosophy of ordinary language and legal realism from speech acts theory are shown. It is concluded

\footnotetext{
${ }^{1}$ Los autores de este artículo han contribuido en partes iguales.

${ }^{2}$ Licenciado en Filosofía por la Universidad del Zulia (Venezuela). Magíster en Lingüística y Enseñanza del Lenguaje por la Universidad del Zulia (Venezuela). Experiencia docente en la Universidad Católica Cecilio Acosta - UNICA (Venezuela), en la Universidad José Gregorio Hernández (Venezuela) y en el Instituto Universitario de Tecnología READIC-UNIR (Venezuela). Correo electrónico: angelmolina20@gmail.com

${ }^{3}$ Abogado por la Universidad del Zulia (Venezuela). Magíster en Derecho Laboral por la Universidad del Zulia (Venezuela). Doctor en Ciencias Gerenciales por la Universidad Dr. Rafael Belloso Chacín - URBE (Venezuela). Posdoctor en Estado, Políticas Públicas y Paz Social por la URBE (Venezuela). Posdoctor en Integración y Desarrollo de América Latina por la URBE (Venezuela). Posdoctor en América Latina y su inserción en el Orden Global por la Universidad Andina Simón Bolívar (Quito-Ecuador). Docente investigador en la Universidad Metropolitana (Ecuador). Docente en la Universidad Técnica Particular de Loja (Ecuador). Correo electrónico: abogcarlosduran@hotmail.com
} 
that the renewed validity of legal realism requires an understanding of its philosophical foundations.

\section{Keywords}

Legal Realism, Empiricism, Logical Positivism, Speech Acts.

\section{Introducción: el realismo jurídico en su contexto}

El realismo jurídico surgió en respuesta a las concepciones del derecho que no se enfocaban en los hechos, sino en abstracciones. Una perspectiva formalista tradicional podía fundarse en la autoridad académica y sus interpretaciones estar dotadas de coherencia lógica, pero sus conclusiones usualmente no tenían correspondencia empírica. Es decir, los realistas denuncian la necesidad de prestar atención al hecho jurídico para observar los criterios extrajurídicos de los jueces y las consideraciones no dispuestas en la norma, lo que sucede efectivamente en los juzgados y no lo que se asume que debería ocurrir según los textos legales.

Aunque se haga referencia al realismo jurídico en un sentido general, hay diferencias notables entre el realismo jurídico continental y el realismo jurídico americano. El realismo jurídico continental, surgido en Suecia y con vigorosas escuelas en Italia ${ }^{4}$ y Francia, tiene claras influencias filosóficas y las plasma explícitamente en sus reflexiones. Por su parte, el realismo jurídico americano plantea un cuestionamiento metodológico al formalismo normativo, optando por un enfoque práctico, ajustado a los hechos, a lo que sucede en la corte, al comportamiento de los actores y a la predictibilidad de los resultados partiendo de un enfoque descriptivo. En tal sentido, la versión estadounidense se enfoca más en el derecho aplicado, en las situaciones concretas y en la utilidad para el ejercicio profesional de anticipar las decisiones de los jueces considerando sus criterios implícitos. Al respecto, dice Leiter: "Los realistas eran juristas (y, algunos, científicos sociales), no filósofos, y sus motivaciones fueron, por tanto, diferentes. Como juristas, ellos estaban actuando contra el "formalismo" o la "jurisprudencia mecánica" de sus días" (Leiter, 2015, p. 241).

A pesar de los matices y de las influencias específicas de cada pensador, hay un aspecto común a ambos lados del Atlántico: una postura epistemológica empirista, consciente o no, propia de la tradición anglosajona y del positivismo sociológico del siglo XIX, el cual pretendía emular el perfeccionamiento del método científico en las ciencias naturales y trasladarlo a las ciencias humanas. Pese a la crítica implacable y los resultados mixtos de esta exportación metodológica, lo cierto es que la perspectiva positivista-cientificista de las $\mathrm{Hu}$ manidades dio origen a las ciencias humanas tal como las entendemos actualmente; ya sea por asimilación o reacción, el resultado es la diversidad de disciplinas y subdisciplinas humanas de nuestros días, con instrumentos metodológicos cuantitativos, cualitativos, interdisciplinariedad, etc. La ciencia jurídica es una de ellas, y el realismo jurídico es consecuencia del Zeitgeist de la segunda mitad del s. XIX y la primera del s. XX. De hecho, se ha hablado de una cosmovisión y mentalidad jurídica realista, que traspasa fronteras y que se evidencia si se consideran factores distintos a la adjudicación y validez jurídica, tales como "el historicismo jurídico crítico, el escepticismo moral secular y las teorías del conflicto sobre el derecho" (Malminen, 2019, p. 155). En ese período visagra, el paradigma científico contemporáneo se asienta y

\footnotetext{
${ }^{4}$ Sobre los juristas analíticos italianos y el realismo de la escuela de Génova, véase Maldonado Muñoz (2020). El autor referido comenta que el artículo Scienza del diritto e analisi del linguaggio de Norberto Bobbio, publicado en 1950, representa, para los integrantes de aquella escuela, la piedra fundacional de su concepción del derecho (2020, p. 15). Sobre el artículo de Bobbio, su contexto e implicaciones, véase Soto Guerrero (1999).
} 
prueba su eficacia en diversas áreas del pensamiento, fenómeno con el que convivieron los intelectuales de la época. Por lo tanto, incluso si la finalidad de algunos realistas jurídicos es estrictamente práctica, sus afirmaciones contienen presupuestos filosóficos propios de una tradición de pensamiento que permeó la cultura anglosajona y tuvo una notable influencia en el resto del mundo, a saber, el empirismo británico. No es coincidencia que, precisamente, hayan surgido en el Reino Unido y los Estados Unidos escuelas filosóficas cuyo criterio de validez epistemológica o ética sea la utilidad o practicidad en la experiencia concreta. Tal es el caso del utilitarismo inglés (Jeremy Bentham y John Stuart Mill) y del pragmatismo estadounidense (Charles Sanders Peirce, William James y John Dewey, entre otros). En este orden de ideas, resaltamos la importancia histórica del positivismo jurídico de fuente utilitarista planteado por John Austin 5 , jurista que perteneció al círculo intelectual de Jeremy Bentham y James Mill, padre de John Stuart Mill. A su vez, el jurista Oliver Wendell Holmes Jr., precursor del realismo jurídico americano, tuvo influencia tanto de los utilitaristas británicos como de los pragmatistas americanos ${ }^{6}$.

Una definición integradora del realismo jurídico, que abarca las diversas corrientes y perspectivas, la ofrece Giuseppe Lumia:

El realismo jurídico constituye el encuentro, en el terreno de los estudios sobre el Derecho, de los puntos de vista epistemológicos del neopositivismo con las doctrinas psicosociológicas, comportamentistas y pragmatistas dominantes en la cultura americana y no extrańas a ciertos ambientes europeos. Del neopositivismo de la Escuela de Viena el realismo jurídico repite los presupuestos metodológicos de la Ciencia del Derecho; pretende en efecto borrar de la Ciencia del Derecho cualquier referencia al deber-ser, no sólo en el significado trascendental que a este término daba la doctrina del derecho natural, sino también en el significado que le atribuye Kelsen, de mera categoría lógico-trascendental; e intenta reducir el conocimiento jurídico a términos de enunciados sobre la realidad (Lumia, 1971, p. 188) ${ }^{7}$.

Resulta interesante que la influencia de la filosofía anglosajona en el realismo jurídico (aunque, esta vez, fundamentalmente en la versión europea) se extiende y consolida en derivaciones de la filosofía analítica, tales como la filosofía del lenguaje ordinario. A diferencia del enfoque logicista y cientificista de la primera ola de la filosofía analítica (con Bertrand Russell, George Edward Moore y Ludwig Wittgenstein entre sus representantes), de destacada influencia en el neopositivismo (que veremos más adelante), la filosofía del lenguaje ordinario estudia el lenguaje natural como acto, en su expresión concreta, con sus particularidades, intenciones y efectos. Así, esta corriente (con John Langshaw Austin, el propio Wittgenstein en su versión tardía y John Searle como referentes) mantiene el enfoque fáctico y la preocupación por el lenguaje de sus predecesores, pero desde la complejidad intrínseca de su objeto de estudio.

\footnotetext{
${ }^{5}$ Dice Robert N. Moles: "Although written in the early nineteenth century, Austin's is probably the most coherent and sustained account of the theory of legal positivism. The complex relationships between legal positivism and the concepts of morality and politics are explored by him but are often neglected or misunderstood in modern commentaries" (Moles, $1998, \mathrm{~s} / \mathrm{p})$.

${ }^{6}$ Allen Mendenhall afirma: "It is true that, after the Civil War, during his studies at Harvard Law School and shortly thereafter, Holmes read Bentham and Austin and seemed to have read every major legal mind in the AngloAmerican legal tradition, and also that the influence of these jurisprudents played into his pragmatism, especially into his "bad man theory," but I believe, with regard to Holmes's influences, these jurisprudents are secondary to Emerson and the classical pragmatists" (Mendenhall, 2015, s/p).

${ }^{7}$ Citado y traducido por Hierro (1996, pp. 78-79)
} 


\section{El empirismo británico como sustrato epistemológico del realismo jurídico}

El empirismo británico (conocido habitualmente como empirismo inglés, pese a que sus principales representantes también son oriundos de otros territorios de las islas británicas), sostiene que el origen del conocimiento está en la experiencia sensible. Según los partidarios de esta corriente filosófica, desarrollada entre los siglos XVII y XVIII, los datos de los sentidos son la fuente y justificación de nuestros pensamientos. Asimismo, desconocen la existencia de ideas innatas y evidentes en la mente humana: el espíritu está vacío antes de cualquier contacto con los objetos sensibles. En tal sentido, el empirismo está en franco antagonismo al racionalismo, la otra corriente filosófica que moldeó la Modernidad y cuyos principales representantes fueron Descartes, Spinoza, Malebranche y Leibniz. Veamos las propuestas de los pensadores clásicos más representativos de esta corriente: John Locke, George Berkeley y David Hume.

Para John Locke (1632-1704), la mente es una tabula rasa; no existe nada en ella hasta que se tiene contacto con los objetos empíricos, externos al sujeto pensante ${ }^{8}$. De manera que el primer pensamiento de la mente es consecuencia inmediata de la primera sensación. Todo lo que ocupa al espíritu son las ideas; término que en Locke tiene un sentido muy general, análogo a la noción de pensamiento en Descartes. Así, idea puede ser —entre otras cosas - una imagen, un concepto o una sensación.

Por otra parte, Locke establece una distinción de las ideas: las ideas pueden ser simples, si son recibidas pasivamente, y complejas, si son generadas por la mente. Entre las simples, están las recibidas por la sensación (experiencia externa) y las recibidas por la reflexión (experiencia interna). Asimismo, la experiencia externa nos presenta cualidades primarias (extensión, número, solidez, etc.) y secundarias (olor, sabor, color, etc.), objetivas y subjetivas respectivamente. Por su parte, las ideas complejas resultan de la puesta en ejecución de alguna de las tres operaciones básicas de la mente sobre las ideas: combinación, comparación y separación (abstracción).

El planteamiento epistemológico de George Berkeley (1685-1753) parte de negar la posibilidad de abstracción. No podemos pensar los objetos más allá de su determinación particular, es imposible pensarlos de modo separado, "en abstracto". Las ideas sólo son particulares: las llamadas "ideas generales" son, en realidad, ideas particulares que representan a las que son similares. Asimismo, rechaza la distinción entre cualidades primarias y secundarias: toda cualidad primaria requiere alguna secundaria para poder ser percibida; por ejemplo: la extensión requiere del color para ser captada; ambos tipos de cualidades son subjetivas.

Estas críticas desembocan en un inmaterialismo solipsista: no podemos decir que existen objetos materiales, "materia" es una abstracción que no se sigue válidamente de la percepción. Sólo podemos expresarnos acerca de nuestras percepciones, que son de índole subjetiva; sólo podemos adjudicarle existencia a nuestras percepciones, ya que sólo tenemos acceso a ellas: esse est percipi (ser es ser percibido). Aquí observamos que el empirismo, llevado hasta sus últimas consecuencias, desemboca en subjetivismo o escepticismo.

\footnotetext{
8 "Supongamos, pues, que la mente sea, como se dice, un papel en blanco, limpio de toda instrucción, sin ninguna idea. ¿Cómo llega entonces a tenerla? [...] ¿De dónde extrae todo ese material de la razón y del conocimiento? A estas preguntas contesto con una sola palabra: de la experiencia; he aquí el fundamento de todo nuestro saber, y de donde en última instancia se deriva: «las observaciones que hacemos sobre los objetos sensibles externos, o sobre las operaciones internas de nuestra mente, las cuales percibimos, y sobre las que reflexionamos nosotros mismos, son las que proveen a nuestro entendimiento de todos los materiales del pensar». Estas son las dos fuentes de conocimiento de donde parten todas las ideas que tenemos o que podemos tener de manera natural" (Locke, 1980, p. 164).
} 
David Hume (1711-1776) desarrolla los planteamientos de sus predecesores. El pensador escocés denomina percepción a toda representación mental, siendo quizá equivalente a la idea en Locke. Las percepciones pueden ser impresiones (internas o externas), si son vivas y se reciben directamente, e ideas, si son la copia o recuerdo fijado en la mente, de carácter débil, de tales impresiones. Asimismo, las impresiones e ideas pueden ser simples o complejas: una impresión simple puede ser un color, mientras que una compleja puede ser un objeto (del cual se observa cierta forma) con un color; las ideas simples y complejas pueden ser la representación mental remanente de la impresión simple o compleja correspondiente, aunque hay muchas ideas complejas que no corresponden directamente con impresiones, sino que son creadas por la mente.

La creación de tales ideas complejas es posible de efectuarse relacionando las ideas, que en Hume no es otra cosa que la asociación de las mismas. Existen tres tipos de asociación: por semejanza, contigüidad y causalidad.

Lo más importante de la distinción entre impresiones e ideas es que estas últimas se justifican por aquellas: una idea es verdadera si podemos establecer el vínculo con la impresión de la cual se origina. En este sentido, la idea — verbigracia - del principio de causalidad no se puede justificar a partir de la experiencia, ya que no podemos ubicar una impresión que efectivamente nos muestre la conexión causal necesaria entre objetos; tal conexión la asumimos por mera costumbre?

\section{La influencia del neopositivismo, deudor del empirismo británico, en el realismo jurídico europeo}

El siglo XX trajo consigo un importante entusiasmo por el conocimiento científico, lo cual motivó a la reflexión filosófica acerca de sus métodos, límites y condiciones. De esta manera, y teniendo como antecedentes los estudios de científicos y filósofos decimonónicos como John Stuart Mill, William Whewell, John Herschel, Henri Poincaré y Ernst Mach, surge el Círculo de Viena, grupo de discusión considerado como fundador de la Filosofía de la Ciencia entendida como disciplina filosófica ${ }^{10}$.

De profundo espíritu cientificista, los integrantes de este grupo pretendieron establecer un lenguaje unificador para las ciencias naturales, basado en datos sensoriales. Por su marcado empirismo y su convencimiento de que la lógica simbólica es la herramienta de análisis más potente y adecuada para la filosofía, el movimiento fue conocido como Empirismo Lógico, Positivismo Lógico, o bien como Neopositivismo. A pesar de la asociación inme-

\footnotetext{
9 "We are determined by custom alone to suppose the future conformable to the past. When I see a billiard-ball moving towards another, my mind is immediately carry'd by habit to the usual effect, and anticipates my sight abstractly considered, and independent of experience, which leads me to form any such conclusion: and even after I have had experience of many repeated effects of this kind, there is no argument, which determines me to suppose, that the effect will be conformable to past experience. The powers, by which bodies operate, are entirely unknown. We perceive only their sensible qualities: and what reason have we to think, that the same powers will always be conjoined with the same sensible qualities?" (Hume, 2007, p. 138-139).

${ }^{10}$ La existencia de este grupo se remonta al menos hasta 1924, con el nombre de Círculo de Schlick, en honor a Moritz Schlick, profesor de física alemán que lo organizó. No obstante, se establece como "Círculo de Viena" a partir de 1929, con la publicación del manifiesto La concepción científica del mundo: El Círculo de Viena. Algunos integrantes a destacar, además del propio Schlick, son Rudolf Carnap, Otto Neurath, Herbert Feigl, Hans Hahn, Philipp Frank, el prominente lógico y matemático Kurt Gödel, así como Friedrich Waismann. También se fundaron dos grupos satélite de ideas afines, a saber, el Grupo de Berlín, que incluía a Hans Reichenbach, Kurt Grelling y Carl Hempel como figuras destacadas y el Círculo de Varsovia, al que pertenecieron lógicos notables como Alfred Tarski y Jan Lukasiewicz. Para un comentario más amplio del desarrollo histórico del movimiento, sus principales representantes y características generales de su pensamiento, véase la Introducción de Ayer a su clásica antología del positivismo lógico (Ayer, 1981).
} 
diata con la corriente fundada por Auguste Comte, como una suerte de renovación de los planteamientos del pensador francés del s. XIX, los neopositivistas se vieron principalmente influidos por Mach, Poincaré o Russell (Echeverría, 1989, p. 7).

También conviene aclarar que Hans Kelsen (1881-1973), prominente representante del positivismo jurídico y profesor de la Universidad de Viena mientras el Círculo de positivistas lógicos desarrolló sus actividades, tuvo cierta afinidad con algunos planteamientos neopositivistas, pero no perteneció a él. De hecho, el normativismo de Kelsen es incompatible con la apelación a la prueba empírica del neopositivismo y, bajo el esquema de esta corriente, peca de idealismo. A su vez, Kelsen tuvo un intercambio dialéctico con los miembros del grupo. Por ejemplo, se opuso a la concepción de la ética de Schlick. Además, Neurath criticó recurrentemente la Teoría pura del derecho de Kelsen (Jabloner, 1998, p. 378). Apartando la coincidencia nominal y el enfoque antimetafísico común, hay notables diferencias conceptuales entre el positivismo jurídico kelseniano y el positivismo lógico, y este último tiene mayor proximidad epistemológica con el realismo jurídico. No en balde, Alf Ross se refiere al planteamiento de Kelsen como "casi positivismo" (Barberis, 2015, p. 238), lo que tal vez también denote una diferencia de grado: el realismo jurídico es más positivista que el positivismo jurídico. Al respecto, dice Barberis: "el realismo jurídico se distingue netamente sólo del iusnaturalismo, pero que cada vez con mayor frecuencia se presenta como una radicalización del positivismo jurídico" (Barberis, 2015, p. 227).

El empirismo del neopositivismo no sólo cuestionó la validez epistemológica de las proposiciones sin sustento empírico, sino que incluso las consideró seudoproposiciones carentes de significado. La subordinación del significado de una expresión a la vinculación directa o indirecta de un correlato empírico verificable implicó un rechazo a la metafísica, considerada por los neopositivistas como una ocupación intelectual estéril y sin sentido. A este respecto, dice Rudolf Carnap, en su célebre artículo La superación de la metafisica a través del análisis lógico del lenguaje: "En el campo de la metafísica (incluyendo la filosofía de los valores y la ciencia normativa), el análisis lógico ha conducido al resultado negativo de que las pretendidas proposiciones de dicho campo son totalmente carentes de sentido" (Carnap, 1981, p. 66).

Nótese que Axel Hägerström (1868-1939), fundador del realismo jurídico escandinavo, coincide con la concepción antimetafísica del neopositivismo y se expresa en términos equivalentes a Carnap:

In his account of his own philosophy in Die Philosophie der Gegenwart in Selbstdarstellungen (1929), Hägerström adopted as motto a modified version of Cato's aphorism, praeterea censeo metaphysicam esse delendam: Metaphysics is nothing but a compilation of words which happen to be connected with emotions. What distinguishes this assumption from other anti-metaphysical positions - quite recurrent in the history of ideas since nineteenth-century positivism - is that the "superstitious" web of metaphysical beliefs spreads its mantle not only over the humanities or Geisteswissenschaften, but over natural science as well (Mindus, 2009, p. XI).

No obstante, la relación entre las ideas de Hägerström y las de Carnap o cualquier otro neopositivista es indirecta: hay una intención paralela de romper con la doctrina académica tradicional, una voluntad de consolidar estrategias cognitivas basadas en la evidencia fáctica, emulando el método científico de enfoque constatativo. Es decir, se trata de una reacción al status quo inope- 
rante y en el que Hägerström se formó en su juventud, de corte idealista hegeliano, neokantiano o, en general, afín a planteamientos metafísicos de su tiempo ${ }^{11}$. A este respecto, comenta Mindus:

Hägerström developed theories in parallel with - yet independently from - some of the major philosophical currents in Europe, namely neo-empiricism and logical positivism. Like the Cambridge and Vienna schools, Hägerström firmly believed in Hume's thesis, the need to distinguish between is and ought, facts and values (Mindus, 2009, p. X).

Otra característica del pensamiento neopositivista es su inductivismo, concepción del método científico que establece que las teorías y leyes científicas se obtienen de modo inductivo: partiendo de la observación cuidadosa, y luego de una comprobación experimental de la muestra tomada, se generalizan leyes y teorías. Ahora bien, el razonamiento inductivo es adecuado e imprescindible para la investigación científica, pero sus conclusiones generales son sólo probables, aun cuando las premisas sean verdaderas.

El probabilismo de esta corriente se explica no solamente por las características propias del razonamiento inductivo, donde la verdad de la conclusión no se sigue con necesidad lógica de la verdad de las premisas, sino también por la aceptación neopositivista de la crítica de David Hume a la inducción y a la causalidad, el llamado Problema de la Inducción. Esta crítica cuestiona la posibilidad de obtener cualquier conocimiento empírico general y de predecir un fenómeno: aunque ciertos acontecimientos hayan sucedido y se hayan repetido hasta ahora con uniformidad y regularidad, esto no implica que se hayan de comportar del mismo modo en el futuro; siempre es posible que la naturaleza cambie, o que se dé un caso distinto a los anteriores. Para Hume, no hay justificación lógica para la creencia en los enunciados obtenidos por vía inductiva, útiles para predecir eventos; estos solo se creen por costumbre.

Empero, la aceptación de los neopositivistas del Problema de la Inducción humeano no los lleva a adoptar una postura epistemológica escéptica. Muy por el contrario, la concepción del razonamiento inductivo como inferencia probable condujo a los empiristas lógicos a buscar determinar el grado de confirmación de los enunciados científicos, sean leyes, hipótesis o teorías. Para tales fines, impulsaron y vigorizaron la lógica inductiva.

Si bien no se podría tener una confianza absoluta en una ley confirmada mediante la observación, sí podríamos tener una probabilidad mayor o menor del cumplimiento de un hecho según una ley o teoría determinada. La mayor o menor probabilidad de un enunciado o conjuntos de enunciados científicos nos brindaría, proporcionalmente, una mayor o menor confianza en ellos. En tal sentido, si un enunciado científico tiene un altísimo grado de probabilidad, podemos decir que es verdadero, partiendo de una concepción de verdad como aproximación. De manera que "lo esencial del saber científico es su capacidad de predecir exactamente fenómenos fisiconaturales. Al ser verificada la corrección de una determinada predicción, las teorías y las leyes, si no verificadas, quedan al menos confirmadas, aunque sea parcialmente" (Echeverría, 1989, p. 17). Esta interpretación probabilista de la verdad es suficientemente confiable en la práctica: es improbable que una ley científica que siempre ha funcionado predictivamente pueda fallar y deba ser revisada.

\footnotetext{
${ }^{11}$ Karl Olivecrona, discípulo de Hägerstrom, analiza la interpretación del concepto de derecho en las corrientes antimetafísicas, es decir, naturalistas, empezando por Austin (a quien denomina "el más destacado de los antimetafísicos"), pasando por los realistas norteamericanos, para luego considerar el planteamiento de su maestro Hägerstrom y finalizar con Lundstedt (Olivecrona, 2007, pp. 13-29).
} 
Pese a todo, y después de una época privilegiada de los neopositivistas, surgen dudas y críticas respecto a sus concepciones sobre la ciencia. La estrechez del criterio empirista de significado proposicional, los intentos de cuantificación del grado de probabilidad de un enunciado científico o su traducción a lenguaje fisicalista, ignorar la historia y la sociología de la ciencia como fuentes relevantes para comprender en qué consiste la actividad científica, la distinción entre enunciados teóricos y observacionales (así como la traducción fallida de los primeros en los segundos), fueron algunos de los aspectos cuestionados por sus detractores.

\section{Los actos de habla de Austin y los actos normativos de Ross}

Ante el desgaste de algunas tesis neopositivistas, surgen posturas críticas que mantienen su preocupación por el análisis del lenguaje y su apelación a la observación de los hechos, pero desde una perspectiva más amplia, incluyendo el comportamiento humano y considerando que en la interpretación neopositivista del lenguaje hay un reduccionismo falaz, que no corresponde al lenguaje en su manifestación concreta, como acto comunicativo, razón por la cual falla en explicar el significado de conceptos y expresiones sin un referente empírico, pero cuyos efectos sí son ostensibles, como las expresiones en el ámbito jurídico.

\subsection{La falacia descriptiva}

El planteamiento filosófico-lingüístico de John L. Austin, ligeramente posterior al del Wittgenstein de las Investigaciones filosóficas, coincide en muchos puntos con él. Ambos planteamientos reivindican el factor humano del lenguaje y su concepción como actividad. Así, se sientan las bases de la concepción actual de la pragmática filosófica y lingüística, además del movimiento conocido históricamente como filosofía del lenguaje ordinario ${ }^{12}$.

$\mathrm{Al}$ inicio de sus disquisiciones, Austin asoma las motivaciones de su planteamiento, criticando lo que denomina la falacia descriptiva:

Durante mucho tiempo los filósofos han presupuesto que el papel de un 'enunciado' sólo puede ser 'describir' algún estado de cosas, o 'enunciar algún hecho' con verdad o falsedad [...] en los últimos años, muchas cosas que anteriormente habrían sido aceptadas sin objeciones como 'enunciados' tanto por los filósofos como por los gramáticos, han sido examinadas con renovada atención [...] apareció el punto de vista no siempre expuesto sin un infortunado dogmatismo, de que un enunciado (fáctico) debe ser 'verificable', y esto llevó a pensar que muchos 'enunciados' sólo son lo que puede denominarse seudo-enunciados (Austin, 1990, pp. 41-42).

Austin está haciendo referencia a los neopositivistas lógicos, pertenecientes en su mayoría al Círculo de Viena. Tal como vimos en el punto anterior, los neopositivistas excluían todo enunciado que no describiera la realidad y que no fuera constatable empíricamente, considerándolas expresiones carentes de significado.

\footnotetext{
12 Sobre la influencia que pudo ejercer Wittgenstein sobre Austin, son encontradas las opiniones al respecto, siendo la respuesta más común señalar la dificultad para precisarla. Se podría afirmar que el planteamiento austiniano se gestó por cuenta propia y se apoyó en el planteamiento wittgensteineano. Wittgenstein desarrolló su vida académica en Cambridge y, si bien sus Investigaciones estuvieron completas en 1949, su publicación fue póstuma (1956). Por su parte, Austin es de Oxford, y su obra más célebre también es póstuma, la cual lleva como título Cómo hacer las cosas con palabras. Publicada en 1962, es una recopilación de una serie de conferencias que dictó el filósofo en Harvard en 1955, cuyo contenido representa el desarrollo de las clases que dictó entre 1952 y 1954, tituladas Palabras y acciones. Habría que determinar, para resolver el asunto, si Austin tuvo acceso al segundo planteamiento wittgensteineano antes de su publicación.
} 
En respuesta, Austin revisa algunas expresiones que no encajan en las clasificaciones y requerimientos neopositivistas, pero que aun así son significativas y, además, se caracterizan por hacer una acción cuando se profieren. Surge así una nueva clasificación de las expresiones lingüísticas en dos grupos: constatativas y realizativas.

\subsection{Expresiones constatativas y realizativas}

Las expresiones constatativas, como sugiere su nombre, son las expresiones susceptibles de ser verdaderas o falsas, en función de su constatación empírica. Tales oraciones describen la realidad perceptible. Ejemplos de ellas pueden ser: "Ecuador es un país suramericano" o "Me tropecé con la mesa".

Por su parte, las expresiones realizativas son las que, al ser proferidas, implican sincrónicamente la realización de una acción. "El acto de expresar la oración es realizar una acción, o parte de ella, acción que a su vez no sería normalmente descripta como consistente en decir algo" (Austin, 1990, pp. 45-46).

Estas expresiones se caracterizan por ser oraciones declarativas que van en la primera persona del singular. Por ejemplo, tenemos expresiones como "te prometo que no lo hice" o "te condeno a veinte ańos de prisión”; al momento de proferirse, se realizan.

Las expresiones realizativas, si bien no son susceptibles de verdad o falsedad, son evaluables desde otra dicotomía, pudiendo ser afortunadas o desafortunadas. Son afortunadas cuando se cumplen las condiciones o circunstancias adecuadas para la ejecución de la acción con la proferencia, mientras que son desafortunadas cuando se evidencia una "falta de coincidencia entre lo que el enunciado dice que hace y lo que en realidad hace" (Conesa y Nubiola, 2002, p. 174).

Tales infortunios pueden ser abusos, malas ejecuciones, desaciertos, entre otros. De tal manera que si proferimos el primero de los ejemplos ("te prometo..."), debemos cumplir con la promesa, de lo contrario actuamos de manera abusiva. En el segundo de los ejemplos ("te condeno..."), si no somos un juez y no estamos en una sala de juzgado, nuestra expresión carece de validez.

Ahora bien, la distinción entre enunciados constatativos y realizativos es problemática, con la presencia recurrente de casos intermedios y la consecuente difuminación de la distinción. Este problema propicia un nuevo criterio para la clasificación, basado en la noción de acto: todo uso del lenguaje generalmente implica tres actos simultáneos: locutivo, ilocutivo y perlocutivo.

\subsection{Los actos lingüísticos: locutivo, ilocutivo y perlocutivo}

El acto locutivo es el consistente en decir algo. A su vez, está compuesto por tres elementos: el acto fonético, que consiste en la expresión de sonidos, de fonemas; el acto fático, es decir, la expresión de vocablos o palabras coherentes con un sistema gramatical; y el acto rético, o la proferencia de las palabras -en la línea semántica fregeana- con un sentido y una referencia.

El acto ilocutivo es el realizado al decir algo, la manera en la cual es utilizada la expresión. En este sentido, si alguien dice “¡Cuidado con el carro!”, es para alertar o avisar acerca de un hecho: la inminente colisión con el automóvil.

Las cinco clases generales de verbos ilocutivos que propone Austin (1990, pp. 195-211), sin descartar la posibilidad de superposiciones (verbos en más de una clase), son las siguientes:

- Judicativos, correspondientes a actos jurídicos o estimaciones: absolver, condenar, decretar, calcular, medir, etc. 


\begin{abstract}
- Ejercitativos, referidos al "ejercicio de potestades, derechos o influencia": designar, revocar, reclamar, aconsejar, perdonar, proclamar, etc.

- Compromisorios, los cuales comprometen al emisor a tomar una postura o a realizar una acción: prometer, adoptar, oponerse, apostar, jurar, apoyar, etc.

- Comportativos, que incluyen el sentido de reacción ante la conducta de los demás: pedir disculpas, elogiar, maldecir, felicitar, desafiar, agradecer, etc.

- Expositivos, usados al tener una conversación o bien al argumentar: contestar, suponer, postular, formular, conceder.
\end{abstract}

Por último, el acto perlocutivo es el realizado por decir algo, es el efecto o reacción producido sobre el destinatario del mensaje. Y es que "a diferencia del acto de decir algo, y del acto realizado al decir algo, el acto perlocucionario es el acto realizado por, o a consecuencia de, decir algo" (Muñiz, 1989, p. 152). Retomando el ejemplo anterior (¡Cuidado...!), cuando se enuncia la frase, es con la intención de provocar una reacción en el interlocutor, esto es, que anticipe el posible accidente, alertarlo ante dicha situación.

Así, la nueva distinción austiniana a partir de la noción de acto le adjudica a toda expresión lingüística un carácter realizativo, que va a residir en su fuerza ilocucionaria. Se puede decir, a modo de síntesis, que "cuando decimos algo, lo decimos en un determinado sentido y producimos unos determinados efectos” (Conesa y Nubiola, 2002, p. 176).

\title{
4.4 La crítica de Ross a la oposición constatativo-realizativo
}

Alf Ross parte de la noción de acto lingüístico de Austin y comparte la perspectiva pragmática del lenguaje del filósofo inglés. Sin embargo, expresa serios cuestionamientos a los términos que emplea y enfatiza su opacidad ${ }^{13}$. Mediante categorías lingüísticas tradicionales, como la función (en lugar de la fuerza), o la distinción entre lenguaje indicativo y directivo ${ }^{14}$ (en lugar de expresiones constatativas y realizativas), el filósofo del derecho danés propone una clasificación distinta de los actos lingüísticos.

De hecho, Ross explica el replanteamiento de la oposición inicial de Austin realizativo-constatativo por la presencia de una falacia realizativa, en la cual sólo las expresiones realizativas son actos, mientras que las constatativas se limitan a decir (y no a hacer) algo. El danés va más allá y considera que esta falacia persiste en la clasificación triádica de los actos de habla, lo cual se refleja en la selección de Austin de verbos ilocucionarios, que reflejan de manera distintiva la fuerza de la expresión en la que son usados (Ross, 2006, p. 106). Ross sostiene que cualquier expresión en una situación comunicativa dada, cuya intención no es lo suficientemente clara, puede incluir una frase o un verbo que indiquen de modo explícito su función. Ahora bien, salvo excepciones, suele ser suficiente expresar en

\footnotetext{
13 "Si puede establecerse que los actos lingüísticos de un cierto tipo, habida cuenta de su contenido, están destinados a producir en un oyente normal, en condiciones normales, efectos de un cierto tipo (por ejemplo, efectos cognoscitivos, emotivos o volitivos), se dirá que estos efectos constituyen la función de ese tipo de acto lingüístico. (Austin introdujo el término "fuerza" en lugar de "función”. No lo sigo porque, en mi opinión, su terminología es aquí más oscura que la tradicional)" (Ross, 2006, p. 102). En esta colección de ensayos, estamos haciendo referencia al texto titulado Grandeza y decadencia de la doctrina de las expresiones realizativas.

${ }^{14}$ En Lógica de las normas, Ross desarrolla de manera más amplia, como preámbulo necesario para desarrollar una lógica deóntica, la distinción entre discurso indicativo y directivo, tomando en cuenta sus diferencias y coincidencias en los planos semántico, gramatical y pragmático: "[...] el discurso indicativo y el discurso directivo presentan diferencias a todos los niveles del análisis lingüístico, aunque de diferentes maneras. A nivel semántico hay una clara distinción entre los indicativos y los directivos. Pragmáticamente, la función de los indicativos es adjudicativa, informativa o fabuladora, mientras que los directivos sólo tienen normalmente función directiva. A nivel gramatical la cuestión no está tan clara, pero algunas formas de expresión son especialmente aptas para expresar bien indicativos, bien directivos” (Ross, 1971, p. 72).
} 
lenguaje indicativo las locuciones con función informativa, sin requerir una frase o verbo que la precisen (sería redundante). Por el contrario, cuando la función es de otro tipo, suele ser frecuente la presencia de verbos que indiquen su función; por ejemplo, "le ordeno..." en un contexto normativo es más frecuente que "digo que es un hecho..." en un contexto informativo (Ross, 2006, pp. 108-110).

La crítica de Ross también alcanza la clasificación de verbos ilocutivos de Austin. Ross argumenta que sólo las tres primeras clases de verbos (judicativos, ejercitativos y compromisorios) se usan en contextos lingüísticos de tipo jurídico o de reglas convencionales, mientras que las dos últimas clases (comportativos y expositivos) se usan en otros contextos. Esta situación "refleja una distinción fundamental dentro de estos verbos indicadores de función, distinción que permanece borrosa en la clasificación de Austin en cinco grupos" (Ross, 2006, p. 111). En contraste, Ross propone, para abarcar las tres primeras clases de verbos y sus particularidades, el concepto de acto normativo. A su vez, lo subdivide en acto jurídico y acto convencional.

Los actos jurídicos son una clase de actos operativos humanos (hechos condicionantes de las reglas jurídicas) que consisten en "comunicaciones lingüísticas cuyo efecto jurídico está determinado por el contenido de la comunicación misma, y que de esta manera son instrumentos adecuados para la actividad humana consciente dirigida a la creación de reglas y relaciones jurídicas" (Ross, 2006, p. 111). Algunos ejemplos que ofrece el autor de actos normativos, que abarcan la autonomía privada y la autoridad pública, son una ley, una decisión judicial, un testamento o un contrato.

Los actos convencionales son las expresiones operativas "de acuerdo con la intención de su autor y las palabras utilizadas, pero cuya fuerza no deriva de un orden jurídico, sino de órdenes normativos de diferente tipo, como la moral convencional o las reglas de un juego" (Ross, 2006, 114). Aquí se incluyen acciones que, dependiendo de la situación, pueden ser jurídicas, pero que en general son convencionales y menos precisas. Por ejemplo, prometer algo o ponerle un nombre a alguien o algo.

\section{Conclusiones: el realismo jurídico, su vigencia y su filosofía}

El realismo jurídico, tanto en su versión americana como europea, revela aspectos interesantes para la reflexión jurídica contemporánea. El trasfondo epistemológico empirista modela un enfoque apegado a la evidencia fáctica, pero también al comportamiento humano en su interacción social ostensible, concreta y compleja. De profundo espíritu antimetafísico, renovó la ciencia jurídica y su legado en las academias, así como en la práctica legal, es notorio. La influencia de la cultura anglosajona en todo el orbe, incluyendo sus instituciones, concepciones políticas y legales, augura un incremento en el estudio del realismo jurídico. En este sentido, es conveniente reconocer los criterios que subyacen a dicha corriente, reconociendo, claro está, la diversidad de planteamientos y aproximaciones, algunas veces a través de la práctica jurídica, otras veces a través de la epistemología, de la metodología de la ciencia, o bien desde el análisis del lenguaje.

Pese a las diferencias entre escuelas y autores, existe, tal como se ha mostrado en el desarrollo de este texto, un sustrato epistemológico común, donde el empirismo, el neopositivismo, la filosofía analítica y el giro lingüístico de la filosofía contemporánea han cumplido un rol más o menos fundamental según las peculiaridades de cada momento, escuela o contexto. Pese al decaimiento generalizado del realismo jurídico y la consecuente pérdida de jerarquía y prestigio, la aparición en las últimas décadas de movimientos que parten del realismo jurídico clásico es una muestra de la vigencia de esta corriente. 
En los años setenta del siglo pasado, surgen los Estudios Jurídicos Críticos (Critical Legal Studies, CLS), que vino a revitalizar el realismo jurídico. Leiter (2015) considera que la interpretación realista del CLS es acomodaticia: "inventó su propia versión del Realismo Jurídico, una que caía mejor con sus ambiciones teóricas distintivas” (2015, p. 272). No obstante, como también señala Leiter (2015, p. 272), que el CLS se inspire en los trabajos del Wittgenstein tardío para modificar algunas premisas de los realistas clásicos, siendo el pensador vienés un representante fundamental de la tradición analítica a la que nos hemos referido en este texto, no nos parece una decisión caprichosa o infundada. Por el contrario, consideramos que es consistente con la afinidad conceptual que postulamos.

A su vez, la aparición del Nuevo Realismo Jurídico (New Legal Realism, NLR) ${ }^{15}$, en los primeros años de este siglo, evidencia el interés continuado y las posibilidades del realismo jurídico de adaptarse y complejizarse según los movimientos académicos, las reflexiones filosóficas y los desafíos fácticos que se originen en el devenir social en el que estamos inmersos.

\section{Referencias bibliográficas}

Austin, J. L. (1990). Cómo hacer cosas con palabras. Barcelona: Paidós.

Ayer, A. J. (comp.). El positivismo lógico. México: Fondo de Cultura Económica.

Barberis, Mauro (2015). El realismo jurídico europeo-continental. En Fabra, J. y Núñez, Á. (eds.). Enciclopedia de filosofía y teoría del derecho (pp. 227-240). México: Universidad Nacional Autónoma de México, vol. I.

Carnap, R. (1981). La superación de la metafísica a través del análisis lógico del lenguaje. En Ayer, A. J. (comp.). El positivismo lógico (pp. 66-87). México: Fondo de Cultura Económica.

Conesa, F. Nubiola, J. (2002). Filosofía del Lenguaje, Barcelona: Herder.

Echeverría, J. (1989). Introducción a la metodología de la ciencia. Barcelona: Barcanova.

Hierro, L. (1996). Realismo jurídico. En Garzón, E. y Laporta, F. (eds.). Enciclopedia Iberoamericana de Filosofia: 11. El derecho y la justicia (pp. 77-86). Madrid: Trotta.

Hume, D. (2007). An Enquiry Concerning Human Understanding. Oxford: Oxford University Press.

Jabloner, C. (1998). Kelsen and his Circle: The Viennese Years. European Journal of International Law, 9, 368-385.

Lang, A. (2015). New Legal Realism, Empiricism, and Scientism: The Relative Objectivity of Law and Social Science. Leiden Journal of International Law, 28, 231-254.

Leiter, B. (2015). El realismo jurídico estadounidense. En Fabra, J. y Núñez, Á. (eds.). Enciclopedia de filosofía y teoría del derecho (pp. 241-276). México: Universidad Nacional Autónoma de México, vol. I.

Locke, J. (1980). Ensayo sobre el entendimiento humano. Madrid: Editora Nacional.

Lumia, G. (1971). Il Diritto trae le due culture. Milano: Giuffrè.

Maldonado Muñoz, M. (2020). Presentación del dossier. Realismo jurídico contemporáneo. El realismo jurídico (apuntes para una introducción). Iuris Dictio, 25, 13-25.

\footnotetext{
15 Sobre el NLR, sus fundamentos epistemológicos y sus implicaciones, véase Lang (2015). También comenta Liborio Hierro: "Asimismo, y precisamente criticando esta vinculación exclusiva al programa constructivo de los realistas (el derecho como instrumento) la más reciente corriente de los "Critical Legal Studies" reclama también su filiación realista, si bien vinculada a la recuperación del programa crítico del realismo, el que — a su decir — se perdió posteriormente: la crítica de la indeterminación radical del Derecho y la investigación de su papel ideológico legitimador” (Hierro, 1996, p. 84).
} 
Malminen, T. (2019). Realismo jurídico escandinavo: algunos asuntos inconclusos. Isonomía, 50, 151-173.

Mendenhall, A. (2015). Oliver Wendell Holmes Jr. and the Darwinian Common Law Paradigm. European Journal of Pragmatism and American Philosophy, VII (2), http:// journals.openedition.org/ejpap/411.

Mindus, P. (2009). A Real Mind: The Life and Work of Axel Hägerström. Dordrecht: Springer.

Moles, R. (1998). Austin, John (1790-1859). En Craig, E. (ed.) Routledge Encyclopedia of Philosophy CD-ROM. London: Routledge.

Muñiz, V. (1989). Introducción a la filosofía del lenguaje. Barcelona: Anthropos, vol. II.

Olivecrona, K. (2007). Lenguaje jurídico y realidad. Fontamara: México.

Ross, A. (1971). Lógica de las normas. Tecnos: Madrid.

- (2006). El concepto de validez y otros ensayos. Fontamara: México.

Soto Guerrero, S. (1999). Norberto Bobbio y la ciencia del derecho como análisis del lenguaje. Investigaciones Jurídicas, 9 (67), 791-803. 